\title{
Population ecology of Polydora ligni (Polychaeta: Spionidae). II. Seasonal demographic variation and its potential impact on life history evolution
}

\author{
Roman N. Zajac \\ Graduate Program in Environmental Sciences, The University of New Haven, 300 Orange Avenue, West Haven, \\ Connecticut 06516, USA
}

\begin{abstract}
Seasonal demographic variation was studied in an estuarine population of the opportunistic polychaete Polydora ligni between May 1982 and November 1983 in Alewife Cove, Connecticut. USA. The demography of 15 cohorts settling during this period was analyzed using life cycle graph models. Cohorts settling in spring and early summer had the shortest life spans $(\approx 10 \mathrm{wk})$; highest survivorship over all life cycle stages and adult females produced an estimated maximum of 6 larval broods. Early adult stages contributed most to population growth during this period, and the potential for population growth, $\lambda$, was the highest during the study. Late summer cohorts had low juvenile survivorship, life spans of $\approx 12 \mathrm{wk}$, and females produced a maximum of 8 broods. Later stage females contributed most to population growth, and $\lambda$ values were usually $\leq 1$, indicating population decline. Fall cohorts comprised 2 groups. Early fall cohorts reproduced only in late fall, as females growing into later stages during winter did not reproduce and died before reproduction resumed in spring. These cohorts had low fecundity, 4 to 6 broods female ${ }^{-1}$, and $\lambda \leq 1$. One cohort settled at the beginning of winter and along with late fall cohorts overwintered to produce the following spring's cohorts. Overwintering cohorts had low juvenile but high adult survivorship, extended times to maturity $(\approx 14$ to $20 \mathrm{wk}$ ), the highest mean fecundity, 4 to 8 broods female ${ }^{-1}$ and $\lambda \approx 1$. The results indicate the demography of Polydora ligni exhibits 3 seasonal phases with respect to population growth over the year: (1) a spring/early summer growth period; (2) a late summer/fall transition phase; (3) a late fall/ winter maintenance period. These demographic phases can be related to regular periodic changes in estuarine soft-bottom habitats and can influence the evolution of its life history traits. Seasonal life history patterns were consistent with predictions of life-history models centering on demographic selection. Seasonal changes in demographic selection may act to increase life-history flexibility in Polydora ligni, and in other infaunal opportunists, as a way of maintaining fitness with respect to periodic changes in habitat conditions. Such flexibility may either enhance or diminish its colonizing abilities. Seasonal demographic changes can influence the response of $P$. ligni to benthic disturbances as opportunistic potential falls off after early summer due to life-history shifts
\end{abstract}

\section{INTRODUCTION}

Since the 1970s, when studies by Grassle \& Sanders (1973), Johnson (1973), Grassle \& Grassle (1974) and McCall (1977) focused attention on disturbance, recolonization and succession in soft-sediment habitats, benthic ecologists have been working to understand the population processes of infauna associated with different seral stages. Much of this work has centered on opportunistic polychaetes, which typically recolonize disturbed habitat patches in high numbers. Information on general population characteristics and dynamics have been gleaned from studies of commun- ity-level responses to disturbance (e.g. Rhoads et al. 1978), and laboratory studies have provided more detailed information on factors influencing life history expression and population dynamics (e.g. Rice \& Simon 1980, Redman 1984, Chesney \& Tenore 1985, Tenore \& Chesney 1985, Zajac 1985a, 1986, Levin \& Creed 1986, Levin et al. 1987, Gremare et al. 1988, 1989). However, few field studies have directly addressed the population dynamics of opportunistic polychaetes (Guillou \& Hily 1983, Levin 1984, Tsutsumi \& Kikuchi 1984, Tsutsumi 1987, Marsh \& Tenore 1990), and in particular their demography (Levin \& Huggett 1990). In this paper, I analyze seasonal demographic variation in a 
population of the opportunistic polychaete Polydora ligni Webster and consider relationships among demographic variation, seasonal changes in habitat conditions and opportunistic life histories.

Polydora ligni and other infaunal opportunists are generally viewed as being adapted for continual exploitation of patches with low abundances of competitors and elevated food resources, and successful dispersal to new open patches (Grassle \& Sanders 1973, Thistle 1981, Chesney 1985). Because the formation of open patches and the duration of favorable conditions within such patches are unpredictable, opportunistic species have evolved r-type life histories (e.g. Pianka 1970, McCall 1977). However, stochastic disturbances are only one facet of temporal heterogeneity in softsediment habitats. Seasonal fluctuations in habitat conditions constitute an important selective regime (e.g. MacArthur 1968, Fretwell 1972, Boyce 1979) that will also shape the life history and demographic attributes of opportunistic species living in seasonal environments (Parsons 1983). Thus, on an ecological basis, seasonal changes in population growth rate, survivorship, fecundity and larval output relative to the disturbance regime will influence the ability of opportunists to persist in a given habitat. Indeed, temporal variations in the responses of opportunists to disturbance and subsequent successional changes (Arntz \& Rumohr 1982, Zajac \& Whitlatch 1982 a, b) may result, to a large extent, from seasonal fluctuations in demography of source populations. On an evolutionary basis, their life history attributes may reflect the integrated response to both periodic and stochastic selection regimes (e.g. Stearns 1976). The interactive effect of ambient seasonality and stochastic disturbances can be especially important to infaunal opportunists because these species have semi-continuous reproduction and generation times which can approximate the duration of particular seasonal conditions. Recent field studies of the opportunistic polychaete Streblospio benedicti by Marsh \& Tenore (1990) and Levin \& Huggett (1990) have shown significant seasonal changes in the population characteristics and demography of cohorts recruiting at different times of the year.

To begin to explore these possibilities in Polydora ligni, I determined changes in survivorship and fecundity for cohorts which settled during different seasons of the year under ambient conditions. These vital rates were used to develop demographic projection models (e.g. Caswell 1989) which were analyzed to determine the potential impact of seasonality on the potential for population increase, the contribution of different components of the population to such growth and fitness. The results indicate that $P$. ligni displays significant seasonal variation in its demography under ambient conditions. Based on these results, and information from the Iiterature, a verbal model is presented which shows how seasonal changes in habitat conditions affect demographic traits, which in turn can shape the evolution of its life history traits. It is suggested that the ability to respond in an opportunistic manner following stochastic disturbances is a subset of life-history characteristics evolved to deal with periodic habitat fluctuations.

\section{MATERIALS AND METHODS}

This study was conducted between May 1982 and November 1983 in Alewife Cove, a small estuary in southeastern Connecticut, USA. Biweekly samples were taken to collect data on population abundance, size-structure and individual reproductive characteristics. Study site characteristics, sampling procedures, data collection and seasonal changes in general population characteristics of Polydora ligni during this period are given in Zajac [1991 (companion paper)]. Here, I focus on methods that were used to analyze the demography of the population.

General demographic approach. Life-cycle graphs (Hubbell \& Werner 1979, Caswell 1982, 1989) were used to model and analyze Polydora ligni's demography. A life cycle graph depicts a species life history and is comprised of nodes representing particular stages in the life cycle which are appropriate for estimating vital rates, e.g. age, size or some other attribute. Fig. 1 shows a generalized life cycle graph for $P$. ligni in which 6 nodes are defined: a larval stage (L), 2 juvenile stages

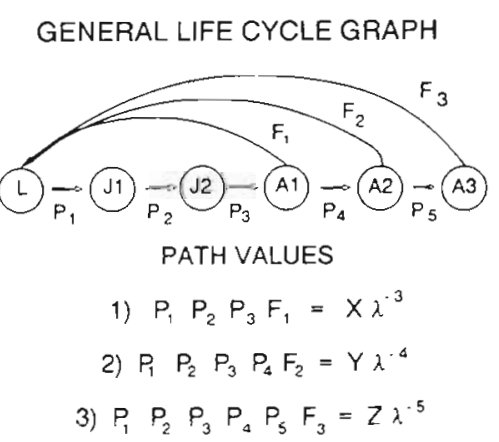

CHARACTERISTIC EQUATIONS
4) $f\left(\lambda^{1}\right)=X \lambda^{3}+Y \lambda^{4}+Z \lambda^{-5}$
5) $\lambda^{N}-\lambda^{N} f\left(\lambda^{1}\right)=0$
6) $\lambda^{5} \cdot X \lambda^{2}-Y \lambda \cdot Z=0$

Fig. 1. Polydora ligni. Generalized life cycle graph. Nodes (L, $\mathrm{J} 1, \mathrm{~J} 2, \mathrm{~A} 1 . \mathrm{A} 2, \mathrm{~A} 3)$ represent successive life-cycle stages; $P_{x}=$ probability of survivorship from one stage to the next; $F_{x}=$ stage-specific fecundity. Eqs. (1) to (3) are reproductive path values; Eq. (4) represents collected path values; Eq. (5) is the general form of the characteristic Eq. (6). See text for details 
( $\mathrm{J} 1$ and $\mathrm{J} 2$ ) and 3 adults stages (A1, A2, A3). The nodes are connected by path arrows depicting transition probabilities of survivorship and/or growth $\left(P_{X}\right)$ into the next node or the reproductive output $\left(F_{x}\right)$ of each node (Fig. 1). The $P_{x}$ transitions are accompanied by a time interval when the transition includes passage of time, which could be weeks, months, years, etc., and is depicted as $\lambda^{-1}$. Time intervals between transitions need not be constant.

Calculation of the population growth rate, $\lambda$, proceeds by first defining each unique reproductive path, which is a complete circuit around the life cycle graph that does not share at least one path with any of the other possible reproductive paths. Each reproductive path's contribution to population growth is determined by taking the product of all the separate path values making up the reproductive path and adding each of the $\lambda^{-1}$ time intervals. For example, in Fig. 1 there are 3 unique reproductive paths. Each of the reproductive path values are then added, collecting terms with the same power of $\lambda^{-1}$, to obtain a polynomial, $f\left(\lambda^{-1}\right)$. This polynomial is then used to calculate $\lambda$ by solving the characteristic equation given in Fig. 1 for its largest real root. $\lambda$ is the rate at which the population grows when a stable stage (age) distribution has been attained. Values of $\lambda=1, \lambda<1$ and $\lambda>1$ indicate population maintenance, decline and growth, respectively. In the analyses that follow, $\lambda$ is interpreted as a relative measure of potential population growth (e.g. Bierzychudek 1982, Levin et al. 1987) and fitness (Charlesworth 1980). Comparisons between $\lambda$ values provide a relative measure of demographic responses to habitat conditions within and among particular portions of the seasonal cycle.

Once $\lambda$ has been calculated, several other demographic characteristics of the population modeled in the life cycle graph can be determined. These include reproductive values, the stage-specific reproductive contribution to population growth (e.g. Charlesworth 1980, Caswell 1982) and sensitivities of $\lambda$ to changes in survivorship and fecundity (Caswell 1978). The analytical formulas I used to calculate these demographic parameters are detailed in Caswell (1982).

Life cycle modelling is a relatively simple, yet flexible approach for demographic analyses. Variations in the life cycle due to factors such as stage duration or changes in larval development mode can be incorporated by adding new nodes and paths (Hubbell \& Werner 1979). In this paper, I consider the demography of individuals whose life history follows the basic model presented in Fig. 1. To detail and analyze temporal changes in the demography of Polydora ligni, a hierarchy of models was used. Separate life cycle graphs were constructed for 'cohorts' settling within each $2 \mathrm{wk}$ sampling period. Vital rates estimated for these individual cohorts were used to develop seasonal life cycle graphs. Seasonal groupings of cohorts were based on their date of settlement relative to changes in overall population abundance (Fig. 1 in Zajac 1991), and for cohorts which settled in the fall, whether they overwintered or not. Seasonal life cycle graphs were then used as components of a yearly life cycle graph for the population. Details of how life cycle graphs for P. ligni were developed and analyzed are given below and also in the results.

Defining life-cycle stages and cohorts. I modeled the Polydora ligni population in Alewife Cove based on the flow of successive cohorts through pre-determined stages. In doing so, several assumptions about individual growth and larval recruitment were made (see 'Discussion'). P. ligni releases primarily 3 setiger larvae which settle at 15 setigers following a period of development ranging between 10 and $21 \mathrm{~d}$ (e.g. Rice 1975). I assumed a $2 \mathrm{wk}$ period of development, except as noted in the results. Following settlement, the growth rate of $P$. ligni at $20^{\circ} \mathrm{C}$ is ca 1 segment $d^{-1}$ (Rice 1975, Zajac 1986). Thus, over a 2 wk period between successive samples, newly settled juveniles would range between 15 and 30 segments, and within the following 2 wk these juveniles would range between 31 and 45 segments. After reaching sexual maturity at 46 to 50 segments, I assumed adults grew a maximum of 10 segments over a 2 wk period based on growth rates observed in the laboratory (Zajac 1986).

Based on these data and assumptions, the following life cycle stages (size-classes) were defined: larvae (L), newly recruited juveniles 15 to 32 segments (J1), juveniles prior to or just attaining sexual maturity 33 to 50 segments (J2), and reproductive adults 51 to 60 segments (A1), 61 to 70 segments (A2), 71 to 80 segments (A3) and > 80 segments (A4). In one case A4 individuals were found to survive beyond a $2 \mathrm{wk}$ period and were designated as $\mathrm{A} 4+$.

During late fall and winter, trends in population sizestructure (Zajac 1991) indicated that growth decreased and therefore it would take longer for worms to grow through successive stages. To incorporate such increases in transition time between stages, it was necessary to increase the $\lambda^{-1}$ time step in the life-cycle graphs. Rice (1978) reported growth rates on the order of half a segment per day at about $15^{\circ} \mathrm{C}$. Therefore, for cohorts which had individuals present between November 8, 1982 and April 4, 1983, transitions into the next stage, for all stages, were assumed to take twice as long, based on a $50 \%$ decrease in the rate of growth. Between January and February, no growth was evident based on size frequency distributions, so no transitions were made into larger size-classes during this period.

Because reproduction and recruitment were continuous, except during the winter (Zajac 1991), a new cohort of juveniles was present on each sampling date. 
I defined cohorts as consisting of all newly settled juveniles (15 to 32 segments) at each sampling date. Fifteen cohorts (designated as C1, C2, C3, etc.) were identified in this manner between May and December 1982. The transition of each cohort through successive stages was then based on the mean density per core of successive stages in successive samples. Limited demographic analyses were performed using data collected on cohorts which settled in 1983 (Zajac 1985b).

Estimating vital rates. In this study, the mean total larval output per core (Fig. 1 in Zajac 1991), across all cohorts, estimated the size of the larval pool (per core) which could potentially settle by the next sampling period. This assumes internal recruitment, but does not make larval survivorship dependent on the subsequent dynamics of the newly formed cohort. Larval survivorship was calculated by dividing the mean number of $\mathrm{J} 1$ individuals per core, comprising a newly settled cohort. by the mean total larval output per core on the preceding sampling date. For each cohort, survivorship to subsequent stages, $l_{x}$, was calculated by dividing the mean number of individuals within a stage by the larval production value used to estimate larval survivorship for that cohort. Abundances of specific stages were derived from data presented in Fig. 2 in Zajac (1991), which depicts temporal changes in population size-structure using the size-classes defined above.

The probability of survivorship from one stage to the next, $P_{x}$, was calculated by

$$
P_{x}=l_{x+1} / l_{x}
$$

Stage-specific fecundity, $F_{x}$, was calculated by averaging individual female fecundity (estimated using methods given in Zajac 1991) within each reproductive stage of each cohort. In cases when only one female's fecundity value was available, this was used as an estimate of $F_{x}$. When no fecundity data on individual females were available, due to either very early stages of egg development or poor preservation, the previous cohort's $F_{x}$ value for that stage was used ( 9 of the $57 F_{x}$ values estimated). Normally the $F_{x}$ estimate would be divided by 2 to reflect the production of female offspring only. However, brood development time is about 6 to $7 \mathrm{~d}$ once females become reproductively active (Rice 1975, Zajac 1986, unpubl.). Therefore, $F_{x}$ values were not halved, since females likely produced 2 broods over the time span between stages, usually $2 \mathrm{wk}$ but longer in late fall and winter.

\section{RESULTS}

\section{Demography of individual cohorts}

The Polydora ligni population studied was comprised of several cohorts at any one time (Table 1). The demo- graphy of the population encompassed the flow of these cohorts through time. Stage-specific transition values for each cohort tracked between May 1982 and April 1983 are shown in Table 1. The most pivotal differences in vital rates among cohorts followed seasonal trends which are presented below. However, there were differences in vital rates over $2 \mathrm{wk}$ periods, i.e. within seasons.

Cohort-specific $\lambda$ values calculated from each life cycle graph (Table 2 ) indicate that $\mathrm{C} 1$, which settled in early May, 1982, had the highest $\lambda . \lambda s$ of cohorts which settled between May and mid-August 1982 steadily decreased, but remained above 1.0 (except C6), indicating a potential for population increase. Cohorts which settled during the late summer and early fall (C8-C11) had $\lambda$ s below 1.0, suggesting population decline. $\lambda s$ of cohorts settling in late fall and winter (C12-C15) generally were above, or very near 1.0 .

\section{Seasonal demographic patterns}

Cohorts which settled in 1982 were grouped (Table 2) based on seasonal trends in population abundance and physical aspects of the environment (Zajac 1985b. 1991), and life-cycle characteristics. C1 settled at the start of the spring increase in population abundance and was designated as a spring cohort. Early summer cohorts, C2-C5, settled during the period of the most rapid increases in population abundance. Late summer cohorts, C6-C9, settled during the period of population decline. Two seasonal life-cycle graphs were constructed for the fall because cohorts C10, C11 and the A1 size-class of $\mathrm{C} 12$ produced larvae which comprised the overwintering cohorts, whereas cohorts C13, C14 and larger C12 females overwintered, along with $\mathrm{C} 15$, and produced the following year's spring cohorts (Table 1). These 2 fall groupings of cohorts are referred to as $F_{w}$ and $F_{s p}$, respectively.

Seasonal stage-specific fecundity was calculated by averaging stage-specific $F_{x}$ values of the cohorts comprising each group. Seasonal $P_{x}$ values were calculated by first averaging $l_{x}$ values of each cohort within the seasonal group and then calculating $P_{x}$ based on the average

Several seasonal trends in the general characteristics of the life history of Polydora ligni were found. The life spans of spring and early summer cohorts were estimated to be on the order of $10 \mathrm{wk}$; few individuals survived to the A4 stage. During the rest of the year, survivorship to the A4 stage and in some cases beyond this stage occurred regularly. As such, the life span increased beyond $10 \mathrm{wk}$ Late summer and early fall cohorts had maximum life spans of 10 to $14 \mathrm{wk}$, while late fall and winter cohorts had maximum life spans of up to $22 \mathrm{wk}$. 
Table 1 Polydora ligni. Stage-specific vital rates for cohorts in Alewife Cove. $P_{x}=$ stage-specific survivorship $F_{x}=$ stage-specific fecundity. $\mathrm{L}=$ larval stage, $\mathrm{J} 1-12=$ juvenile stages, $\mathrm{A} 1-\mathrm{A} 4=$ adult stages

\begin{tabular}{|c|c|c|c|c|c|c|c|c|}
\hline \multirow[b]{2}{*}{ Cohort } & \multicolumn{8}{|c|}{ Transitions and stage-specific survivorship $\left(P_{x}\right)$} \\
\hline & DS & L-J1 & $\mathrm{J} 1-\mathrm{J} 2$ & $\mathrm{~J} 2-\mathrm{A}_{1}$ & $\mathrm{~A} 1-\mathrm{A} 2$ & $\mathrm{~A} 2-\mathrm{A} 3$ & A.3-A. & $\mathrm{A} 4-\mathrm{A} 4+$ \\
\hline $\mathrm{C} 1$ & 7 May & 0.0088 & 0.854 & 0.427 & 0.719 & 1.000 & 0.000 & 0.000 \\
\hline $\mathrm{C} 2$ & $21 \mathrm{May}$ & 0.0055 & 0.391 & 1.000 & 1.000 & 0.216 & 0.000 & 0.000 \\
\hline $\mathrm{C} 3$ & 3 Jun & 0.0040 & 0.450 & 1.000 & 1.000 & 0.250 & 0.017 & 0.000 \\
\hline $\mathrm{C}_{4}$ & $21 \mathrm{Jun}$ & 0.0019 & 0.817 & 1.000 & 0.665 & 0.634 & 0.000 & 0.000 \\
\hline $\mathrm{C} 5$ & 6 Jul & 0.0047 & 0.634 & 0.660 & 0.373 & 0.273 & 0.000 & 0.000 \\
\hline C6 & $20 \mathrm{Jul}$ & 0.0017 & 0.823 & 0.259 & 0.833 & 0.283 & 0.458 & 0.000 \\
\hline $\mathrm{C} 7$ & 4 Aug & 0.0025 & 0.368 & 0.667 & 0.547 & 0.697 & 0.478 & 0.509 \\
\hline $\mathrm{C} 8$ & 19 Aug & 0.00075 & 0.867 & 0.415 & 1.000 & 0.074 & 0.250 & 0.000 \\
\hline $\mathrm{Cg}$ & 30 Aug & 0.00005 & 1.000 & 1.000 & 1.000 & 1.000 & 1.000 & 0.000 \\
\hline $\mathrm{C} 10$ & 15 Sep & 0.00006 & 0.416 & 1.000 & 1.000 & 1.000 & $1.000^{\circ}$ & 0.000 \\
\hline C11 & 29 Sep & 0.0029 & 0.329 & 0.607 & 1.000 & $1.000^{\circ}$ & $1.000^{\circ}$ & 0.000 \\
\hline $\mathrm{C} 12$ & $15 \mathrm{Oct}$ & 0.0021 & 0.256 & 0.516 & $1.000^{\circ}$ & $1.000^{\cdots}$ & $1.000^{\circ}$ & 0.000 \\
\hline C13 & $27 \mathrm{Oct}$ & 0.0071 & 0.631 & $0.334^{\circ}$ & $0.750^{\cdots}$ & $0.660^{\circ}$ & $0.500^{\circ}$ & 0.000 \\
\hline $\mathrm{C} 14$ & 8 Nov & $0.0016^{\circ}$ & $0.385^{\circ}$ & $0.601 \cdots$ & $0.670^{\circ}$ & $1.000^{\circ}$ & 0.000 & 0.000 \\
\hline \multirow[t]{2}{*}{ C15 } & $15 \mathrm{Jan}$ & $0.0004^{\circ}$ & $1.000^{\circ}$ & $1.000^{\circ}$ & $1.000^{\circ}$ & 0.483 & 0.526 & 0.000 \\
\hline & \multicolumn{8}{|c|}{ Stage-specific fecundity $\left(F_{x}\right)$} \\
\hline Cohort & \multicolumn{2}{|r|}{ A1 } & A2 & & & \multicolumn{2}{|l|}{$\mathrm{A} 4$} & $\mathrm{~A} 4+$ \\
\hline $\mathrm{C} 1$ & \multicolumn{2}{|r|}{675} & 1160 & \multicolumn{2}{|c|}{2028} & \multicolumn{2}{|l|}{0} & 0 \\
\hline $\mathrm{C} 2$ & \multicolumn{2}{|r|}{734} & 1237 & \multicolumn{2}{|c|}{1357} & \multicolumn{2}{|l|}{0} & 0 \\
\hline C3 & \multicolumn{2}{|r|}{1028} & 1073 & \multicolumn{2}{|c|}{1667} & \multicolumn{2}{|l|}{3659} & 0 \\
\hline $\mathrm{C} 4$ & \multicolumn{2}{|r|}{950} & 874 & \multicolumn{2}{|c|}{1770} & \multicolumn{2}{|l|}{$\begin{array}{r}3039 \\
0\end{array}$} & 0 \\
\hline C5 & \multicolumn{2}{|r|}{657} & 1093 & \multicolumn{2}{|c|}{1118} & & 0 \\
\hline C6 & \multicolumn{2}{|r|}{871} & 1043 & \multicolumn{2}{|c|}{968} & \multicolumn{2}{|l|}{$\begin{array}{r}0 \\
1764\end{array}$} & 0 \\
\hline $\mathrm{C} 7$ & \multicolumn{2}{|r|}{503} & 1206 & \multicolumn{2}{|c|}{2933} & \multicolumn{2}{|l|}{1764} & 3486 \\
\hline $\mathrm{C8}$ & \multicolumn{2}{|r|}{862} & 950 & & & 3363 & & 0 \\
\hline C9 & & 718 & 950 & & & 3363 & & 0 \\
\hline $\mathrm{C} 10$ & & 718 & 950 & & & 0 & & 0 \\
\hline C11 & & 556 & 400 & & 0 & 0 & & 0 \\
\hline C12 & & 556 & 0 & & & 3765 & & 0 \\
\hline $\mathrm{C} 13$ & & 0 & 0 & & & 2878 & & 0 \\
\hline C14 & & 0 & 1569 & & & 0 & & 0 \\
\hline C15 & & 603 & 1176 & & & 2800 & & 0 \\
\hline
\end{tabular}

Age to maturity was estimated to be fairly consistent throughout the year, with worms becoming sexually active by 6 wk. A significant change, however, took place during the winter as late fall and winter cohorts did not exhibit signs of sexual maturity until 14 to $20 \mathrm{wk}$ of age. This coincided with extended transition times between all stages during the winter (Fig. 2). The maximum number of larval broods produced by females was estimated to be 6 to 8 in spring and early summer cohorts, and 8 in late summer cohorts. The number of possible broods dropped for $F_{w}$ cohorts to 4 to 6 , as many of these individuals died during the winter before egg capsule deposition resumed in the spring. The greatest range in the number of broods produced was estimated for the late fall and winter cohorts. Depending on when these cohorts settled they could produce from 4 to 8 broods of larvae.

Seasonal changes in overall survivorship, $l_{x}$ (Fig. 3), were indicative of organisms having high reproductive output but with few offspring surviving to adult stages. Seasonal differences in survivorship were statistically significant (Table 3). Inspection of the components of the test statistic indicates that the greatest differences can be attributed to high survivorship to all stages in spring and early summer cohorts relative to cohorts which recruited during the rest of the year. With regards to survivorship from one stage to the next, $P_{x}$, during spring, early summer and winter, survivorship from $\mathrm{J} 1$ to $\mathrm{A} 2$ stages was high, and then dropped off. In contrast, during late summer and fall, survivorship declined steadily after the $\mathrm{J} 1$ stage.

To determine the relative variability of survivorship to juvenile versus adult stages among seasons, I calculated coefficients of variation (CV, Sokal \& Rohlf 1981) for $l_{x}$ values obtained for each Polydora ligni stage for each seasonal grouping of cohorts. Several differences 
Table 2. Polydora ligni. Values of $\lambda$ calculated from cohortspecific and seasonal life cycle graphs. The projection period associated with each value of $\lambda$ is 2 wk. C1, C2, refer to individual cohorts tracked during the study period (see 'Materials and Methods'). Cohort-specific values were calculated from life-cycle graphs using vital rate estimates given in Table 1 . Seasonal values were calculated from life-cycle graph models shown in Fig. 2. Seasonal groupings for the cohorts are also shown

\begin{tabular}{|c|c|c|c|c|}
\hline Spring & $\begin{array}{c}\text { Early } \\
\text { summer }\end{array}$ & $\begin{array}{l}\text { Late } \\
\text { summer }\end{array}$ & Fall & Winter \\
\hline \multicolumn{5}{|c|}{ Cohort-specific $\lambda$ values } \\
\hline C1 1.736 & $\begin{array}{ll}\text { C2 } & 1.533 \\
\text { C3 } & 1.513 \\
\text { C4 } & 1.386 \\
\text { C5 } & 1.233\end{array}$ & $\begin{array}{ll}\text { C6 } & 0.937 \\
\text { C7 } & 1.144 \\
\text { C8 } & 0.863 \\
\text { C9 } & 0.809\end{array}$ & $\begin{array}{ll}\text { C10 } & 0.939 \\
\text { C11 } & 0.846 \\
\text { C12 } & 1.038 \\
\text { C13 } & 1.116 \\
\text { C14 } & 0.991\end{array}$ & C15 1.030 \\
\hline \multicolumn{5}{|c|}{ Seasonal model $\lambda$ values } \\
\hline 1.736 & 1.492 & 0.980 & $\begin{array}{ll}F_{\mathrm{w}} & 0.995 \\
F_{s p} & 0.985\end{array}$ & 1.030 \\
\hline
\end{tabular}

emerged (Fig. 4). For early summer cohorts, the CV decreased from $\mathrm{J} 1$ to A1 stages and increased sharply in later stage adults, indicating greater variation in survivorship to these stages. In contrast, for late summer and fall cohorts, the CV decreased in each succes-

\section{SEASON-SPECIFIC LIFE CYCLE GRAPHS}

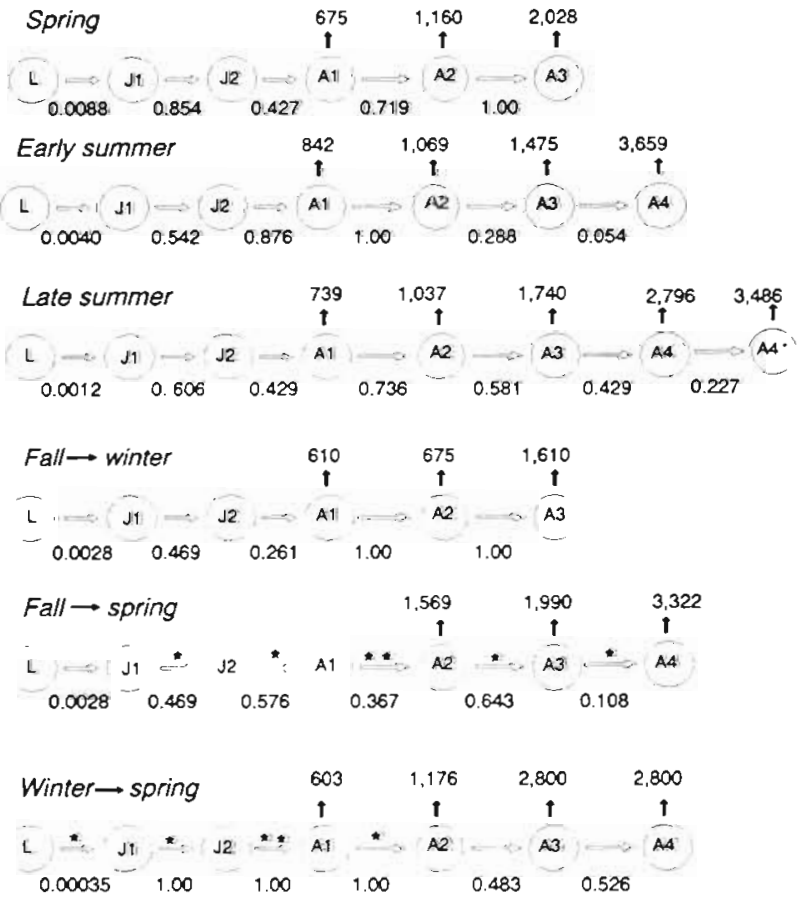

Fig. 2. Polydora ligni. Seasonal life-cycle graphs. Life-cycle conventions as in Fig. 1 and Table 1

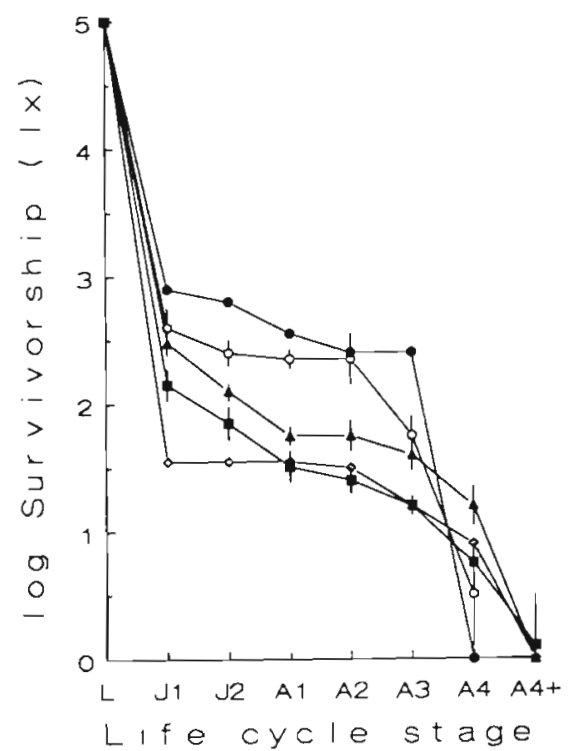

Fig. 3. Polydora ligni. Seasonal variation in mean ( \pm 1 SE) stage-specific survivorship during 1982-1983. Values are survivorship $\left(I_{x}\right)$ per 100000 individuals $\log _{10}$ transformed. Stages

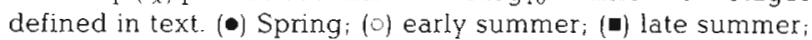

(४) fall; $(\diamond)$ winter

sive stage, indicating more variable juvenile survivorship during these seasons.

Seasonal trends in stage-specific fecundity were less distinct than those found for survivorship (Fig. 5). Statistical analyses detected no significant differences in mean female fecundity among seasons in each adult stage (Table 3). However, there were several interesting trends. The highest A1 fecundity was found in early summer cohorts while for stages A.2, A.3 and A4 the highest fecundity was found in females which overwintered and/or comprised the spring cohort.

Fluctuations in $\lambda$ calculated from seasonal life cycle graph models reflected values obtained from individual cohort models (Table 2). Spring and early summer $\lambda$ s were $>1$; late summer and both fall models yielded values just below 1 while the winter $\lambda$ was just above 1 .

\section{A yearly demographic mode}

Given the seasonal variations in demographic characteristics presented above, what was the potential rate of population growth, $\lambda_{y}$, over the entire year? To estimate $\lambda_{y}$, seasonal life cycle graphs were used to develop a yearly population model (Fig. 6). In this model, reproductive output from one season is channelled totally into the larval stage of the next. This is not a totally accurate depiction of what occurs among seasons, as females reproducing early in a season contribute to that season's cohorts. However, most of a 
Table 3. Polydora ligni. Results of statistical tests of seasonal differences in survivorship and stage-specific fecundity. For survivorship, a $\log$ rank procedure (Pyke \& Thompson 1986) was used to test for a significant difference ( $p<0.05)$ between the curves shown in Fig. 3. Fecundity differences were tested using Kruskal-Wallis tests (Sokal \& Rohlf 1981). df: degrees of freedom; stages explained in test

\begin{tabular}{|c|c|c|c|c|c|}
\hline \multicolumn{6}{|c|}{$\begin{array}{l}\text { Survivorship } \\
\quad \text { Seasonal components of LR }\end{array}$} \\
\hline Log rank statistic (LR) & Spring & E. summer & Seasonal components of LR & Fall & Winter \\
\hline $12.38(4 \mathrm{df}, \mathrm{p}<0.01)$ & 5.49 & 5.19 & 0.07 & 0.15 & 1.48 \\
\hline \multicolumn{6}{|c|}{ Fecundity } \\
\hline Stage & & Test statistic & $\mathrm{df}$ & \multicolumn{2}{|c|}{ Significance } \\
\hline A 1 & & 4.31 & 4 & \multicolumn{2}{|c|}{$p>.10$} \\
\hline $\mathrm{A} 2$ & & 6.13 & $5^{\circ}$ & \multicolumn{2}{|c|}{$p>.10$} \\
\hline A3 & & 2.51 & 5 & \multicolumn{2}{|c|}{$p>.10$} \\
\hline A4 & & 7.28 & 5 & \multicolumn{2}{|c|}{$p>.10$} \\
\hline
\end{tabular}

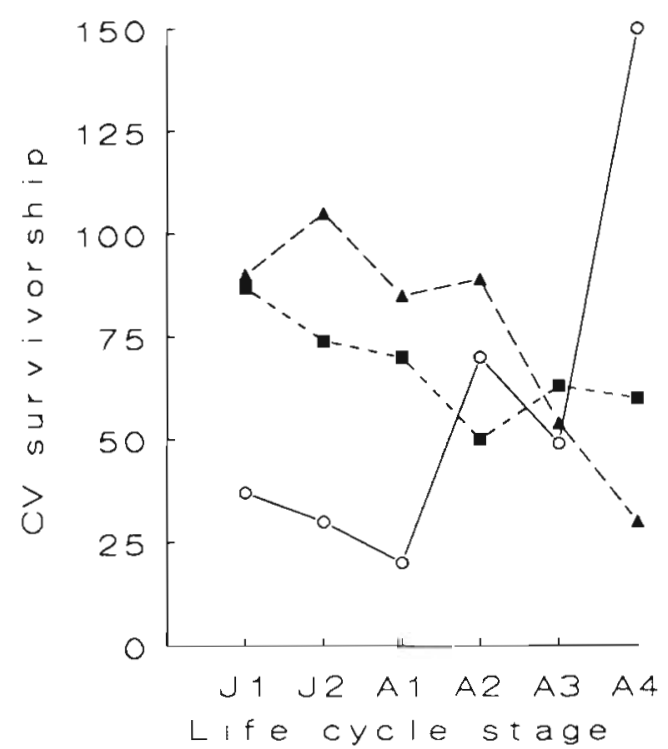

Fig. 4. Polydora ligni. Seasonal changes in the relative variation in survivorship to successive life-cycle stages. For each season, the stage-specific coefficient of variation (CV) was calculated based on values for seasonal groups of cohorts as given in Table $2(\bullet)$ Early summer; ( $)$ late summer; ( $\bullet$ fall

season's reproduction does contribute to the following season's larval pool. $\lambda_{y}$, calculated from the yearly life cycle graph, was 1.159, indicating a potential for longterm increase in population size.

\section{Seasonal changes in related demographic parameters}

Seasonal changes in stage-specific reproductive values (RV) and the sensitivity of $\lambda$ to changes in stagespecific vital rates were calculated for the Polydora ligni

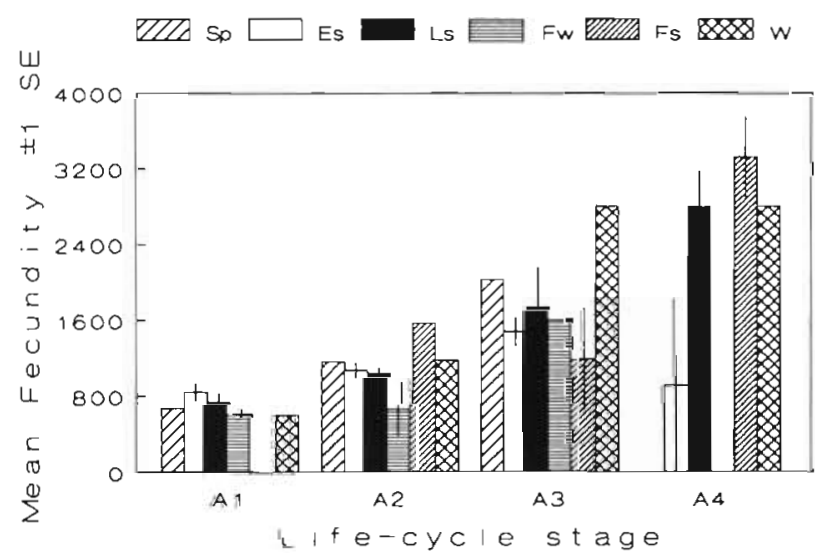

Fig. 5. Polydora ligni. Seasonal changes in stage-specific fecundity (mean \pm 1 SE) during 1982-1983 based on $F_{x}$ values in Table 1. Fall histograms are comprised of 2 groups: $F_{w}$ females which produced late fall and early winter larvae (designated FW on the graph), and $F_{\mathrm{sp}}$ females which produced broods in spring 1983 (designated as FS on the graph). Sp: spring, Es: early summer; Ls: late summer; F: fall, W: winter

population based on seasonal life cycle graphs. The $\lambda_{y}$ value calculated from the yearly population model (Fig. 6) was used in these analyses to obtain information on seasonal differences in these parameters relative to population growth over a yearly cycle. Very similar trends were found when season-specific $\lambda$ s were used in the calculations (R. N. Zajac, unpubl.).

There were distinct seasonal differences in stagespecific reproductive values. RVs were similar for juvenile stages but differences among adult worms were more pronounced (Fig. 7). For spring and early summer cohorts, A1 and A.2 females had the highest RVs. In contrast, for late summer, fall and winter cohorts 


\section{Annual life cycle graph}

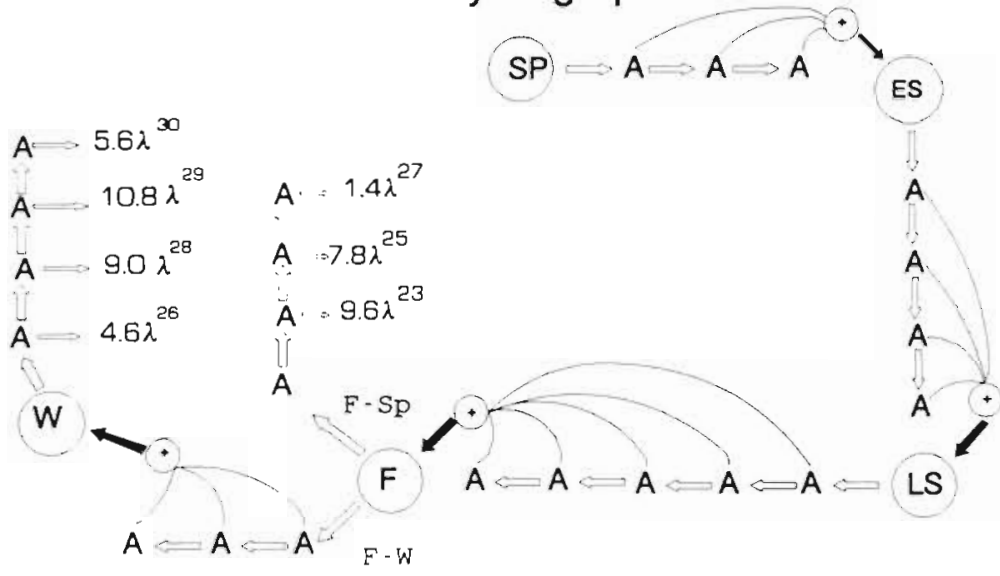

Fig. 6. Polydora ligni. Yearly life-cycle graph for the population inhabiting the Alewife Cove study site based on cohorts tracked between May 1982 and April 1983. Each season is depicted by a larval juvenile pool (represented by the circled seasonal designation) followed by the number of adult stages (A) generally found during each season. For each season, path values were summed (indicated by paths flowing into small circle with $\mathrm{a}+$ ) prior to transition into the next season. Given are time elapsed (in $2 \mathrm{wk}$ intervals) and path values for each adult stage at the end of the cycle

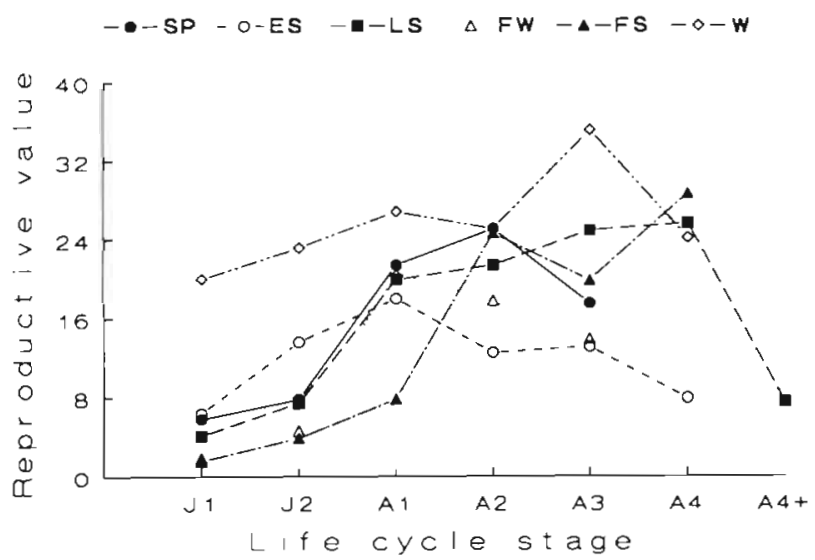

Fig. 7. Polydora ligni. Seasonal changes in stage-specific reproductive values (RV) based on seasonal $P_{x}$ and $F_{x}$ estimates given in Fig. 2. Seasonal designations as in Fig. 5

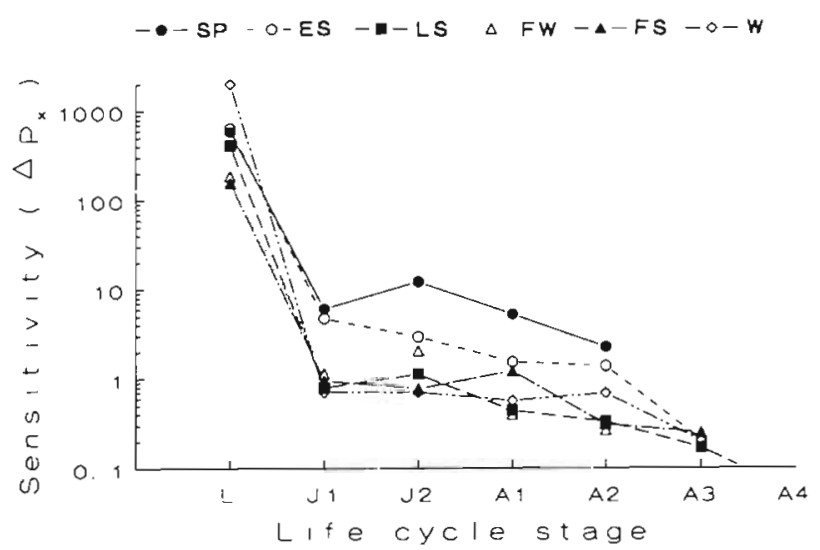

Fig. 8. Polydora lign Sensitivity of $\lambda_{y}$ to changes in survivorship, $P_{x}$, for each seasonal life cycle graph given in Fig. 2. Seasonal designations as in Fig. 5 the highest RVS were found in later adult stages. The only deviation from this trend was found for $F_{w}$ cohorts whose RV pattern was similar to early summer. RVS for the winter cohort were quite different from other seasons. The RV for each stage, especially juveniles, was generally much higher than in any other season, except for A2 and A4 which were equivalent to peak values in other seasons. The highest RV for any stage, within any season, was found for winter A3 females.

Sensitivity of $\lambda_{y}$ to changes in survivorship are shown in Fig. 8. $\lambda_{y}$ was most sensitive to changes in larval survivorship in all seasons. However, the highest sensitivity was found in the winter cohort for this life-cycle transition; the lowest for the fail cohorts. Sensitivity to changes in survivorship to all subsequent stages was greatest in the spring and early summer and decreased during the remainder of the year. Within each season, there was one stage, apart from larval survivorship, in which survivorship changes would have a relatively large impact on $\lambda$. These were survivorship to $\mathrm{J} 2$ in the spring, to $\mathrm{J} 1$ in early summer, late summer and $F_{w}$, to $A 1$ in $F_{\text {sp }}$ and to $A 2$ in winter.

The sensitivity of $\lambda_{y}$ to changes in fecundity (Fig. 9) was either relatively consistent across all stages for a particular season (spring and winter) or decreased steadily in successive stages (summer and fall). Sensitivity to changes in fecundity was highest in the spring and early summer, and decreased in other seasons.

\section{DISCUSSION}

\section{Assumptions}

Several of the assumptions made in order to develop the demographic models presented here should be addressed. I assumed specific growth rates (i.e. life- 


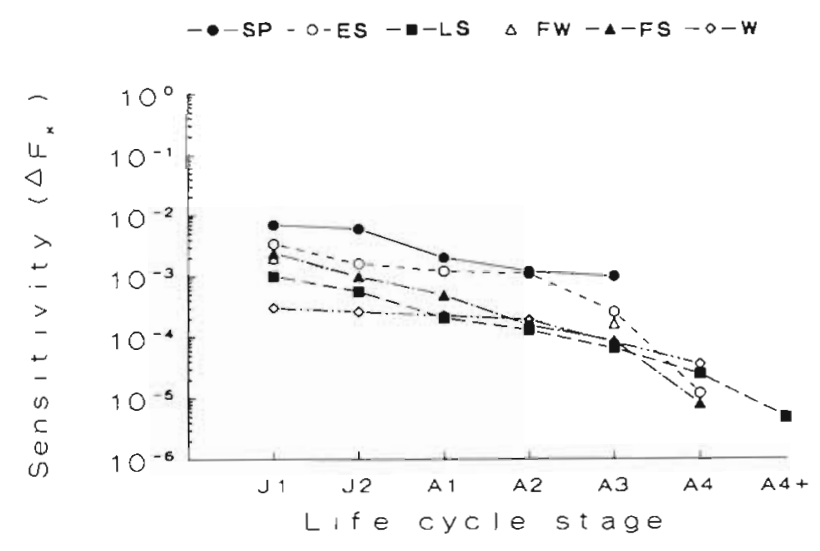

Fig. 9. Polydora ligni. Sensitivity of $\lambda_{y}$ to changes in fecundity, $\Delta F_{x}$, for each seasonal life-cycle graph given in Fig. 2. Seasonal designations as in Fig. 5

cycle transition times) for Polydora ligni for particular times of the year and that these were similar for all individuals within a life-cycle stage. The rates selected were primarily keyed to temperature changes in the environment. Also, adjustments made to reflect slower growth during colder months were discontinuous when in reality they are continuous. Even within seasons when temperature variation is minimal, other local conditions can alter growth (Zajac 1986).

By not being able to distinguish growth differences among cohorts, an unknown but potentially important portion of the demography of Polydora ligni was unaccounted for. However, the size ranges for each lifecycle stage and changes in transition times between stages used here likely accommodated growth variations between individuals of a cohort. In laboratory studies (Zajac 1986), J1 individuals with a mean size of 31 segments grew to 51 segments mean size in $32 \mathrm{~d}$. when exposed to a variety of density and food conditions. The growth rates used in this study would have predicted that these individuals would attain a size between 50 and 60 segments, i.e. within the A1 stage, in $28 \mathrm{~d}$. Because the period between sampling times in this study averaged about $15 \mathrm{~d}$, and the laboratory result fell within the size range for the A1 stage, the growth rates applied to the field population appear to be realistic estimates.

The problem of defining the source(s) of recruits is one that plagues demographic studies of benthic fauna with planktonic larvae (Ayal \& Safriel 1982). This is especially likely for populations inhabiting open coastal habitats, but the situation for estuarine populations, as studied here, can be quite different. A number of larval behaviors and abiotic processes act to return and/or retain larvae in the estuary of origin (e.g. Boicourt 1982, Christy \& Stancyk 1982). Polydora ligni has several types of reproductive behavior which can promote local recruitment, including initial larval development in brood capsules and for a portion of the population, adelphophagia (Zajac 1985b). Thus, it is reasonable to analyze its demography assuming internal recruitment as a first order estimate. We do not know to what extent the larval behavior of $P$. ligni promotes retention or return within Alewife Cove, but it is likely that its estuarine larval populations are not subjected to the extent of mixing depicted for nonestuarine benthic fauna. During this study, peaks of larval production and recruitment were closely related in time (Zajac 1991) and the dynamics of the overall $P$. ligni population in Alewife Cove is fairly synchronous in time (Zajac \& Whitlatch 1982a). Also, while internal recruitment was assumed, I did not calculate larval survivorship of a particular cohort using data on the subsequent reproductive output of the cohort.

Field studies of the demography of infauna have many difficulties, but can lead to important insights regarding infaunal dynamics (e.g. Weinberg et al. 1986). Despite the inevitable assumptions which have to be made, a range of dynamics can be defined and analyzed on a relative basis using reasonable estimates of particular parameters, such as growth, and taking a reasonable view of dispersal interactions among local populations. The resulting analyses are equivocal, but I feel they do add to the continuing refinement of our empirical knowledge of infaunal population dynamics.

\section{Environmental determinants of seasonal demographic changes}

The demography of Polydora ligni exhibited distinct seasonal phases over the course of this study: (1) a spring and early summer growth period, (2) a late summer and early fall transition period, (3) a late fall and winter maintenance period. Seasonal changes in a number of abiotic and biotic factors could shape the population's demography during each of these 3 phases. In the spring and early summer, high survivorship over the entire life cycle (Fig. 3) resulted in the highest $\lambda$ s found during the study (Table 2). Spring and early summer cohorts recruited into a basically open habitat, relatively devoid of potential competitors and predators which could increase mortality and reduce growth via interspecific interactions. Infaunal density at the study site is at its yearly low by the end of winter (Zajac \& Whitlatch 1982a). Perhaps more importantly, benthic algal blooms (Admiraal \& Peletier 1980) and sedimentation from planktonic algal blooms (Graf et al. 1982, Marsh \& Tenore 1990) likely provided elevated food resources during this period, leading to high survivorship. In a recent study, Marsh \& Tenore (1990) 
found that maximal growth and reproduction in Streblospio benedicti, another opportunistic polychaete. occurred during early spring and coincided with elevated phytodetrital sedimentation.

During early summer, fecundity in A2 and A3 stages decreased from spring levels, as did survivorship to the A3 stage. This was apparently in response to progressive decreases in habitat suitability due to increasing density and falling food resources. However, demographic dynamics in the spring and early summer, especially in juvenile and early adult stages, lead to a sharp increase in population abundance and larval production during the early summer (Zajac 1991). A large larval pool and elevated abundance at this time would bolster population numbers prior to and during the late summer and early fall transition phase

During summer and early fall, demographic characteristics of Polydora ligni shifted. There was low survivorship during early life-cycle stages during this period, leading to a decline in population abundance (Zajac 1991) and $\lambda_{s}<1$. However, maximum life span (Table 1) and contributions by later stage adults to population growth (Fig. 7) increased. Elevated infaunal densities during summer months (e.g. Zajac \& Whitlatch 1982a, Levin 1984) can reduce space and food resources. Concurrently, the activity of epifaunal browsers and bioturbators (Myers 1977, Curtis \& Hurd 1981, Dobbs 1981) and predatory infauna increase (Zajac unpubl.). Together, these factors may have contributed to the low survivorship and potential population growth found during this period (Table 2, Fig. 3). Several studies have shown that these factors can reduce infaunal survivorship and reproductive activity (e.g. Wilson 1983, Woodin 1983, Zajac 1985a, 1986) and potential population growth rates (Pesch et al. 1987). In particular, survivorship from the larval to J1 stage declined during this period. Adult-larval interactions in soft-bottom communities at and/or just following settlement have been implicated in having an important effect on determining local abundance and population growth (e.g. Woodin 1976). The results suggest that for $P$. ligni any such interactions may be most critical during late summer and early fall, given the high sensitivity of $\lambda_{y}$ to changes in larval survivorship during this period (Fig. 8). With regard to food resources, Marsh \& Tenore (1990) have suggested that shortages in micronutrients, such as essential fatty and amino acids, may be an important determinant of declines in abundances of opportunistic species during summer.

During late fall and winter, demographic changes resulted in is stabilizing at equilibrium levels. In temperate estuarine environments, this period is marked by reductions in infaunal and epifaunal abundances (Zajac \& Whitlatch 1982a) and increases in potential food resources (e.g. Whitlatch 1981). Thus, cohorts recruiting during late fall and winter experienced conditions that may have been akin to those in the early spring. Interestingly, early stage survivorship for the winter cohort was the lowest found (Fig. 3). This may have been due to harsh winter conditions. To a great extent, life history changes during winter were also a result of low temperatures reducing activity and growth rates. At lower temperatures development time increases, in turn increasing the transition time between life-cycle stages (Table 1). These were important shifts in the rate of demographic change, in addition to changes in the level of survivorship and fecundity

Female Polydora ligni grew to large sizes during winter, albeit slowly due to low temperatures, and accumulated large numbers of gametes (Zajac 1991). During this period, there were extensive diatom blooms at the study site which could have acted as an important food source. Once reproduction resumed in the spring, females had high fecundity. As a result, copious numbers of larvae are produced at the start of the period most favorable for population expansion. High fecundities were found in early spring (Fig. 2, Zajac 1991) when overwintering cohorts began to produce broods.

Significant seasonal demographic changes have also been found in populations of Streblospio benedicti, although the pattern of demographic changes varied from that found in this study (Levin \& Huggett 1990). Summer and fall cohorts of Streblospio benedicti had the highest population growth rates; spring cohorts made the lowest contribution to annual population growth. As in P. ligni, there were seasonal changes in the relative contribution of different demographic components and life-cycle stages to population growth (Levin \& Huggett 1990).

Seasonal changes in the demography of Polydora ligni may have important consequences with regard to its ability to respond to disturbances in soft-sediment habitats. In studies of successional dynamics in Alewife Cove (Zajac \& Whitlatch $1982 \mathrm{a}$, b), responses of $P$. ligni to disturbance were greatest during spring and early summer and fell off considerably during the remainder of the year. Temporal variation in responses of opportunistic infauna to disturbance have been shown in other studies (Arntz \& Rumohr 1982, Bonsdorff 1989) In their demographic study of Streblospio benedicti. Levin \& Huggett (1990) found that demes with planktotrophic larvae exhibited strong seasonality in recolonization of disturbed patches. In general, temporal differences in the response to disturbance by opportunistic polychaetes may be due to seasonal demographic changes reducing larval production and the ability of recolonizing populations to exploit disturbed habitat patches. 


\section{Seasonal demographic selection of life history}

Generation time of Polydora ligni and its life span coincide closely to the periodicity of seasonal changes in temperate soft-sediment communities. Cohorts which settled at different times af the year experienced different environmental conditions. The population dynamics of $P$. ligni is a function of the integrated demographic attributes of successive cohorts during each season over the course of a full year (Fig. 6). However, a particular suite of evolved life history traits suitable for one season may not be totally suitable in another. In response to temporal and spatial heterogeneity, a variety of species have evolved flexible life histories (Nichols et al. 1976). The changing demographic dynamics exhibited by $P$. ligni may reflect such flexibility.

Seasonality may be an important determinate of lifehistory flexibility (Stearns 1976, Grassle \& Grassle 1977, Whittaker \& Goodman 1979, Caswell 1983). I suggest that seasonally varying demographic selection operating via 'bet hedging' may be the basis for the evolution and maintenance of a flexible life history in Polydora ligni. Bet hedging models of life history evolution (e.g. Stearns 1976) center on the relative degree of variation in juvenile versus adult mortality and predict opposing suites of traits depending on which of these demographic conditions exists (Table 4). In this case, environmental conditions promoting high variation in either juvenile or adult survivorship are not temporally constant, but shift seasonally, Cohorts in different seasons experience different selective regimes and over time a flexible life history may emerge to maximize fitness across seasons in the periodic environment.

In early summer, the adult survivorship of Polydora ligni was more variable than juvenile survivorship, but this difference progressively reversed itself during late summer and fall (Fig. 4). Seasonal shifts in the life history of $P$. ligni during this study correspond to bet hedging predictions under these conditions (Table 4). For spring and early summer cohorts of $P$. ligni, the life span was shorter (Fig. 2), the fecundity of A1 and A2 females was higher than in other seasons, except winter (Fig. 5), fewer broods were deposited and early stages contributed most to population growth (Fig. 7). In late summer and fall, the life span was longer, so more broods could be developed, and fecundity increased in later adult stages which contributed most to population growth.

Environmental conditions which can cause the relative degree of juvenile versus adult survivorship to vary seasonally in the direction found may occur regularly in temperate estuarine environments. During spring and early summer, both water column and benthic habitat conditions may be more predictable and homogenous, thus reducing variation in the survivorship of individuals which recruit and mature during this period. For example, phytoplankton blooms during spring and early summer occur yearly in New England water (Pratt 1965, Nixon \& Oviatt 1973), and provide an abundant food source for planktotrophic larvae. Since Polydora larvae ingest phytoplankton at a rate proportional to its concentration (Turner \& Anderson 1983), high concentrations may reduce residence time of larvae in the plankton and in turn reduce the risk of starvation and predation by other zooplankton and nekton. Also, potential predators of larvae such as jellyfish and ctenophores were present in Alewife Cove between mid-summer and fall but not in spring and early summer (own obs.). Finally, as larvae settle during this period, sedimentation from phytoplankton blooms provide a regular source of food (see above) which could further decrease survivorship variation in benthic juvenile stages. Benthic conditions during spring and early summer may further reduce variation in juvenile mortality owing to reduced densities and activities of competitors, predators and bioturbators

Changes in seasonal conditions from midsummer

Table 4. Polydora ligni. Life-history characteristics in fluctuating environments predicted by $\mathrm{r}-\mathrm{K}$ and bet-hedging models. See text for references

Population conditions

Density-independent mortality fluctuations in population

Adult mortality varies

Juvenile mortality varies
Life history traits

$\mathrm{r} / \mathrm{K}$ selection theory

Early maturity, small body size, large broods, high reproductive output, density repeated colonization, short lifespan, tendency towards semelparity

Bet-hedging models

Early maturity, large broods, high reproductive output, short life span, tendency towards semelparity

Late maturity, smaller broods, low reproductive output, longer lifespan, iteroparity 
through early fall may cause the variation in juvenile survivorship to increase. Phytoplankton and zooplankton blooms become sporadic and the incidence of epibenthic and nektonic predators increases (Nixon \& Oviatt 1973). In the benthos, the increased activity of an array of infauna and epifauna may cause habitats to become much more patchy during summer and early fall in terms of their attraction and quality for recruiting juveniles, relative to spring conditions. For example, the gastropod Ilyanassa obsoleta is an important epibenthic bioturbator at the study site, occurring in spatially variable aggregations when it is most active between July and September (own obs.). During the rest of the year the snails were confined to deeper habitats along marsh banks. I. obsoleta can consume large numbers of spionids (Curtis \& Hurd 1981) and can significantly reduce larval settlement and juvenile recruitment of infauna (Hunt et al. 1987). During summer, adult/juvenile interactions could increase variation in juvenile survivorship also, as adult stages of infauna increase in abundance in variable aggregations. Food resources may also become more patchily distributed. Boyce (1979) has noted that resource shortage periods can generate strong selective pressures in a seasonal environment. Such shortages occur during summer and can impact juvenile stages of opportunistic species (Marsh \& Tenore 1990), increasing variation in survivorship.

Factors increasing variation in juvenile survivorship for cohorts settling in mid-summer to late summer may act similarly on aduits of spring and early summer cohorts which become reproductive at this time. Increased variation in both adult and juvenile survivorship during this period may be especially important with regard to selection of flexible life history traits in Polydora ligni. As abundances and activities of infauna and epifauna decrease during fall and into winter, habitats may become less heterogeneous and more open. Increases in surface organic matter derived from fall diatom blooms and senescing plants in adjacent saltmarshes (see above) may provide food resources to adults during the fall and winter As a result, variation in adult survivorship may diminish for cohorts which settled during late summer and early fall

In summary, seasonality generates habitat conditions causing temporal gradients in the relative degree of variation in juvenile and adult survivorship in Polydora ligni. This leads to demographic selective pressures which favor different life history characteristics at different times of the year To maintain populations in fluctuating environments, theoretical work suggests that a mixed, or flexible, life history may evolve which attempts to maximize the organism's fitness over all conditions (e.g. King \& Anderson 1971, Roughgarden 1971, Whittaker \& Goodman 1979). I suggest that the life history of $P$. ligni, and perhaps of other opportunistic infauna which have similar life history characteristics, has evolved in this manner.

In suggesting the above scenario, I do not necessarily discount the importance of current views centering on selective pressures associated with environmental stochasticity in shaping the life history of opportunistic infauna (Grassle \& Sanders 1973, Grassle \& Grassle 1974, McCall 1977). As Boyce (1984) has pointed out, life-history evolution in seasonal environments may not be simply reduced to one set of selective factors but rather may involve some combination of several sets of factors. Indeed, there may be an interplay between selective pressures associated with stochastic and periodic aspects of the environment in shaping life history traits associated with opportunism. However, these may act in both a complementary and antagonistic fashion over a seasonal cycle

In the Polydora ligni population studied, demographic conditions during spring and early summer yielded the highest cohort-specific $\lambda s$, which maximized population expansion during the most favorable portion of the seasonal cycle. Spring and early summer habitat conditions can be viewed as analogous to conditions generated by disturbances in soft-sediment environments $_{i}$ in both situations there are open patches with elevated food resources. Spring and early summer cohorts produced the most larvae (Zajac 1991), but more importantly perhaps, their life history was conducive to rapid population growth and patch exploitation. The ability to quickly exploit resources in an open patch via rapid sexual maturation and reproduction may have a greater impact on population maintenance in a heterogeneous environment than Iarval dispersal to find open patches. During spring and early summer therefore, selective pressures associated with environmental uncertainty and seasonality would be complementary by operating in the same direction. In both cases, $r$-type (Table 4) life history traits would be favored.

In contrast, cohorts making up the population during the rest of the year exhibited life-history traits which decreased the potential of Polydora ligni to respond to disturbances and quickly build up populations in open patches. Larval production declined (Zajac 1991), life spans increased and later stages of the life cycle contributed most to population growth. These appear to be adaptations to maintain populations under deteriorating habitat conditions, as suggested in the previous section. Thus, selective pressures associated with these traits would be antagonistic to the maintenance of opportunistic traits. Although the life history of P. ligni enables it to respond in an opportunistic manner following disturbance, such traits may not evolve and be maintained strictly in response to selective pressures generally associated with opportunists, e.g. environ- 
mental unpredictability, poor competitive ability and high food supply requirements. Seasonality in habitat conditions giving rise to demographic fluctuations also appears to be critical.

Acknowledgements. This research was submitted in partial fulfillment of the requirements for the Ph.D. degree, Biological Sciences Group (Ecology). The University of Connecticut. During the period this work was being done I benefited from the support and stimulation of numerous colleagues, friends and my family. My associate advisors J. P. Grassle and S. W. Pacala, along with J. A. Silander, C. W. Schaffer, S. Y Feng, B. $L$. Welsh and F. Streams provided many insightful comments and suggestions. C. I. Katz, E. A. Matson, F. C. Dobbs, J. R. Weinberg, V. R. Starzack, S. Edwards, D. J. Waslenchuk, W. B. Lyons, M. E. Hines and B. Lussier provided assistance with various aspects of this study and/or were instrumental along various portions of the learning curve, and with their mates provided the necessary diversions. My major adviser R. B. Whitlatch excelled in all these areas. Financial support was provided, in part, by The American Museum of Natural History Lerner Grey Fund for Marine Research, predoctoral fellowships from the University of Connecticut, and NSF Grant OCE 80144 7 (to R. B. Whitlatch). Technical support was provided by A. Lima, R. DeGoursey, D. Good, E. Wessels and C. Crouch. Easy access to the study area was provided by the Town of Waterford, Connecticut. Jakym Zajac, Frances Z. Calafiore, her family and my children gave the encouragement and support without which this work would not have been possible. The manuscript was improved by comments from E. D. Gallagher K. Tenore, L. A. Levin, A. Marsh and several anonymous reviewers. To all I extend my deepest thanks.

\section{LITERATURE CITED}

Admiraal, W., Peletier, H. (1980). Influence of seasonal variations of temperature and light on the growth rate of cultures and natural populations of intertidal diatoms. Mar. Ecol. Prog. Ser. 2: 35-43

Arntz, W. E., Rumohr, H. (1982). An experimental study of macrobenthic colonization and succession, and the importance of seasonal variation in temperate latitudes. J. exp mar. Biol. Ecol. 64: 17-45

Ayal, Y., Safriel, U. N. (1982). r-Curves and the cost of the planktonic stage. Am. Nat. 119: 391-401

Bierzychudek, P. (1982). The demography of Jack-in-the-pulpit, a forest perennial that changes sex. Ecol. Monogr 52: $335-351$

Boicourt, W. C. (1982). Estuarine larval retention mechanisms on two scales. In: Kennedy, V. (ed.) Estuarine comparisons. Academic Press, New York, p. 445-457

Bonsdorff, E. (1989). Infaunal colonization and its dependence on environmental variation - experimental evidence from the northern Baltic Sea. In: Ryland, J. S., Tyler, P. A. (eds.) Reproduction, genetics and distributions of marine organisms. Olsen \& Olsen, Fredensborg, p. 349-356

Boyce, M. S. (1979). Seasonality and patterns of natural selection for life histories. Am. Nat. 114: 569-583

Boyce, M. S. (1984). Restitution of $r$ - and K-selection as a model of density-dependent natural selection. A. Rev Ecol. Syst. 15: $427-448$

Caswell, H. (1978). A general formula for the sensitivity of population growth rate to changes in life history parameters. Theort Popul. Biol. 14: 215-230
Caswell, H. (1982). Stable population structure and reproductive value for populations with complex life cycles. Ecology 63: $1223-1231$

Caswell, H. (1983). Phenotypic plasticity in life history traits demographic effects and evolutionary consequences. Am Zool. 23: 35-46

Caswell, H. (1989). Matrix population models. Sinauer Associates, Inc, Sunderland

Charlesworth, B. (1980). Evolution in age-structured populations. Cambridge University Press, Cambridge

Chesney, E. J. (1985). Succession in soft-bottom benthic environments: are pioneering species really outcompeted? In: Gibbs, P. E. (ed.) Proceedings 19th European Marine Biological Symposium. Cambridge University Press, Cambridge, p. 277-286

Chesney, E. J., Tenore, K. R. (1985). Oscillations of laboratory populations of the polychaete Capitella capitata (Type I): their cause and implications for natural populations. Mar Ecol. Prog. Ser 20: 289-296

Christy, J. H., Stancyk, S. E. (1982). Timing of larval production and flux of invertebrate larvae in a well mixed estuary. In: Kennedy, V. (ed.) Estuarine comparisons. Academic Press, New York, p. 489-503

Curtis, L. A., Hurd, L. E. (1981). Nutrient procurement strategy of a deposit feeding neogastropod, llyanassa obsoleta. Estuar. coast. Shelf Sci. 13: 277-285

Dobbs, F. C. (1981). Community ecology of a shallow subtidal sandflat, with emphasis on sediment reworking by $\mathrm{Cly}_{y}$ menella torquata (Polychaeta: Maldanidae). Masters thesis, University of Connecticut, Storrs

Fretwell, S. D. (1972). Populations in a seasonal environment Princeton University Press, Princeton

Graf, G., Bengston, W., Diesner, V., Schulz, P., Theede, H (1982). Benthic responses to sedimentation of a spring phytoplankton bloom: process and budget. Mar. Biol. 67: 201-208

Grassle, J. F., Grassle, J. P. (1974). Opportunistic life histories and genetic systems in marine benthic polychaetes. J. mar. Res. 32: 253-284

Grassle, J. F., Grassle, J. P. (1977). Temporal adaptations in sibling species of Capitella. In: Coull, B. C. (ed.) Ecology of marine benthos. University of South Carolina Press, Columbia, p. 177-189

Grassle, J. F., Sanders, H. L. (1973). Life histories and the role of disturbance. Deep Sea Res. 20: 643-659

Gremare, A., Marsh, A. G., Tenore, K. R. (1988). Shortterm reproductive responses of Capitella sp. I (Annelida: Polychaeta) fed on different diets. J. exp mar. Biol. Ecol. 123: $147-162$

Gremare, A., Marsh, A. G., Tenore, K. R. (1989). Secondary production and reproduction of Capitella capitata type I (Annelida: Polychaeta) during a population cycle. Mar. Ecol. Prog. Ser. 51: 99-105

Guillou, M., Hily, C. (1983). Dynamics and biological cycle of a Mellinna palmata (Ampharetidae) population during the recolonisation of a dredged area in the vicinity of the harbour of Brest (France). Mar. Biol. 73: 43-50

Hubbell, S. P., Werner, P. A. (1979). On measuring the intrinsic rate of increase of populations with heterogenous life histories. Am. Nat. 113: 277-293

Hunt, J. H., Ambrose, W. G., Peterson, C. H. (1987). Effects of the gastropod, Ilyanassa obsoleta (Say), and the bivalve, Mercenaria mercenaria (L.), on larval settlement and juvenile recruitment of infauna. J, exp. mar. Biol. Ecol. 108 229-240

Johrison, R. G. (1973). Conceptual models of benthic communities. In: Schopf, T. J. M. (ed.) Models in paleobiology. Freeman Cooper and Co., San Francisco, p. 148-159 
King, C. E., Anderson, W W. (1971). Age-specific selection. II. The interaction between $r$ and $K$ during population growth. Am. Nat. 105: 137-156

Levin, L. A. (1984). Life history and dispersal patterns in a dense infaunal polychaete assemblage: community structure and response to disturbance. Ecology 65: 1185-1200

Levin, L. A., Creed, E. L. (1986). Effect of temperature and food availability on reproductive responses of Streblospio benedicti (Polychaeta: Spionidae) with planktotrophic or lecithotrophic development. Mar. Biol. 92: 103-113

Levin, L. A., Caswell, H., DePatra, K. D., Creed, E. L. (1987). Demographic consequences of larval development mode: planktotrophy vs. lecithotrophy in Streblospio bendicti. Ecology 68: 1877-1886

Levin, L. A., Huggett, D. V. (1990). Implications of alternative reproductive modes for seasonality and demography in an estuarine polychaete. Ecology 71: 2191-2208

MacArthur, R. H. (1968). Selection for life tables in periodic environments. Am. Nat. 102: 381-393

Marsh, A. G., Tenore, K. R. (1990). The role of nutrition in regulating the population dynamics of opportunistic, surface-deposit feeders in a mesohaline community. Limnol. Oceanogr. 35: 406-420

McCall, P. L. (1977). Community patterns and adaptive strategies of the infaunal benthos of Long Island Sound. J. mar Res. 35: 221-266

Myers, A. C. (1977). Sediment processing in a marine subtidal sandy bottom community. II. Biological consequences. J. mar. Res. 35: 633-647

Nichols, J. D., Conley, W., Batt, B., Tipton, A. R. (1976) Temporally dynamic reproductive strategies and the concept of $r$ - and K-selection. Am. Nat. 110: 995-1005

Nixon, S. W., Oviatt, C. A. (1973). Ecology of a New England salt marsh. Ecol. Monogr. 43: 463-498

Parsons, P. A. (1983). The evolutionary biology of colonizing species. Cambridge University Press, Cambridge

Pesch, C. E., Zajac, R. N., Whitlatch, R. B., Balboni, M. (1987). The effects of intraspecific density on the life history traits and population growth rate of Nereis arenacoedentata (Polychaetea, Nereidae) in the laboratory. Mar Biol. 96. $545-554$

Pianka, E. R. (1970). On I- and K-selection. Am. Nat. 104 $592-597$

Pratt, D. M. (1965). The winter-spring diatom flowering in Narragansett Bay. Limnol. Oceanogr 10: 173-184

Pyke, D. A., Thompson, J. N. (1986). Statistical analysis of survival and removal rate experiments. Ecology 67.240-245

Redman, C. M. (1984). Effect of temperature and salinity on the life history of Capitella capitata (Type I). Dissertation, City University of New York, New York

Rhoads, D. C., McCall, P. L., Yingst, J. Y. (1978). Disturbance and production on the estuarine seafloor Am. Sci. 66: $557-586$

Rice, S. A. (1975). The life history of Polydora ligni (Polychaeta: Spionidae) including a summary of reproduction in the family Spionidae. Masters thesis, California State University, Long Beach

Rice, S. A. (1978). Intraspecific variation in the opportunistic polychaete Polydora ligni (Spionidae). Dissertation, University of South Florida, Tampa

Rice, S. A., Simon, J. L. (1980). Intraspecific variation in the pollution indicator polychaete Polydora ligni (Spionidae) Ophelia 19: 79-115

This article was presented by K. R. Tenore, Solomons, Maryland, USA
Roughgarden, J. (1971). Density-dependent natural selection. Ecology 52: 453-468

Sokal, R. R., Rohlf, F. J. (1981). Biometry. W. H. Freeman and Co., New York

Stearns, S. C. (1976). Life history tactics: a review of the ideas Quat. Rev. Biol. 51: 3-47

Tenore, K. R., Chesney, E. J. (1985). The effects of interaction of rate of food supply and population density on the bioenergetics of the opportunistic polychaete Capitella capitata (type I). Limnol. Oceanogr. 30: 1188-1195

Thistle, D. (1981). Natural physical disturbances and com. munities of marine soft-bottoms. Mar. Ecol. Prog. Ser. 6 223-228

Tsutsumi, H. (1987). Population dynamics of Capitella capitata (Polychaeta: Capitellidae) in an organically polluted cove. Mar. Ecol. Prog. Ser. 36: 139-149

Tsutsumi, H., Kikuchi, T (1984). Study of the life history of Capitella capitata (Polychaeta: Capitellidae) in Amakusa south Japan including a comparison with other geographical regions. Mar. Biol. 80: 315-321

Turner, J. T., Anderson, D. M. (1983). Zooplankton grazing during dinoflagellate blooms in a Cape Cod embayment. with observations of predation upon tintinids by copepods Pubbl. Staz. zool. Napoli I: Mar. Ecol. 4: 359-374

Weinberg, J. R., Caswell, H., Whitlatch, R. B. (1986). Demographic importance of ecological interactions: how much do statistics tell us? Mar. Biol. 93: 305-310

Whitlatch, R. B. (1981). Animal-sediment relations in intertidal marine benthic habitats: some determinants of deposit-feeding species diversity. J. exp. mar Biol. Ecol. 53: $31-45$

Whittaker, R. H., Goodman, D. (1979). Classifying species according to their demographic strategy. I. Population fluctuations and environmental heterogeneity. Am. Nat. 113 $185-200$

Wilson, W H. Jr (1983). The role of density dependence in a marine infaunal community. Ecology 64: 295-306

Woodin, S. A. (1976). Adult-larval interactions in dense infaunal assemblages: patterns of abundance. J. mar. Res. 34: $25-41$

Woodin, S. A. (1983). Biotic interactions in recent marine sedimentary environments. In: Tevesz, T J. S., McCall, P. L. (eds.) Biotic interactions in recent and fossil benthic communities. Plenum Press, New York, p. 3-38

Zajac, R. N. (1985a). The effects of sublethal predation on reproduction in the spionid polychaete Polydora ligni Webster. J. exp. mar. Biol. Ecol. 88: 1-19

Zajac, R. N. (1985b). Population dynamics and life history variation in Polydora ligni (Annelida: Polychaeta). Dissertation, University of Connecticut, Storrs

Zajac, R. N. (1986). The effects of intraspecific density and food supply on growth and reproduction in the infaunal polychaete Polydora ligni. J. mar. Res. 44: 339-359

Zajac, R. N., Whitlatch, R. B. (1982a). Responses of estuarine infauna to disturbance. I. Spatial and temporal variation of initial recolonization. Mar Ecol. Prog. Ser. 10: 1-14

Zajac, R. N., Whitlatch, R. B. (1982b). Responses of estuarine infauna to disturbance. II. Spatial and temporal variation of succession. Mar. Ecol. Prog. Ser 14: 15-27

Zajac, R. N. (1991). Population ecology of Polydora lign (Polychaeta: Spionidae). I. Seasonal variation in population characteristics and reproductive activity. Mar Ecol. Prog. Ser. 77: 197-206

Manuscript first received: November 11, 1990

Revised version accepted: August 30, 1991 